\title{
Current transport mechanism in InGaP/GaAsSb/GaAs double-heterojunction bipolar transistors
}

\author{
B. P. Yan, ${ }^{\text {a) }}$ C. C. Hsu, X. Q. Wang, and E. S. Yang \\ Department of Electrical and Electronic Engineering, The University of Hong Kong, Pokfulam Road, \\ Hong Kong SAR, People's Republic of China
}

(Received 15 June 2004; accepted 24 August 2004)

\begin{abstract}
We have developed InGaP/GaAsSb/GaAs double-heterojunction bipolar transistors (DHBTs) with low turn-on voltage and high current gain by using a narrow energy bandgap GaAsSb layer as the base and an InGaP layer as the emitter. The current transport mechanism is examined by measuring both of the terminal currents in forward and reverse mode. The results show that the dominant current transport mechanism in the InGaP/GaAsSb/GaAs DHBTs is the transport of carriers across the base layer. This finding suggests that the bandgap offset produced by incorporating $\mathrm{Sb}$ composition into GaAs mainly appears on the valence band and the conduction-band offset in InGaP/GaAsSb heterojunction is very small. (C) 2004 American Institute of Physics.
\end{abstract}

[DOI: $10.1063 / 1.1808891]$

GaAs-based heterojunction bipolar transistors (HBTs) have been widely used for power amplifiers in wireless and high-speed digital applications. However, GaAs-based HBTs have a relatively large base-emitter turn-on voltage due to the large bandgap of GaAs used as the base layer, and this limits the minimum operating voltage and increases the power consumption in circuit applications. In addition, both AlGaAs/GaAs and semi-ordered InGaP/GaAs HBTs suffer from current gain degradation at elevated temperature because of a low valence-band offset $\Delta E_{v}{ }^{1,2}$ reducing power capacity. Therefore, it is important to develop material combination HBTs with low turn-on voltage and thermal stability. The material combination HBTs should meet following requirements: (1) the base layer should use lower energy bandgap materials to reduce the turn-on voltage; (2) the emitter-base (EB) junction should have a large valence-band offset $\Delta E_{v}$ and a small conduction-band offset $\Delta E_{c}$; (3) the conduction-band discontinuity $\Delta E_{c}$ in the base-collector (BC) junction should be very small such that no collector current blocking effect occurs. Recently, several groups have demonstrated the potential of using narrow energy bandgap InGaAsN material in the base layer to reduce the turn-on voltage. ${ }^{3-6}$ However, InGaAsN material typically displays degraded minority carrier properties compared with GaAs, leading to the reduction of dc current gain and high frequency performance. Although these unfavorable characteristics can be suppressed by the insertion of graded layers between the base and collector junction, ${ }^{4}$ this complicates the transistor design and fabrication.

Another attractive narrow bandgap base material is $\mathrm{GaAsSb}$, which has been successfully used in InP-based HBTs by Bolognesi et al. ${ }^{7,8}$ In comparison with a latticematched GaAs base, the smaller band gap of GaAsSb can reduce the turn-on voltage, thus the power dissipation in circuits. Moreover, the band lineup at the GaAsSb/GaAs interface is inferred to be a staggered ("type II") lineup," that would eliminate the current blocking. Although GaAs-based HBTs with GaAsSb base layers have been reported, ${ }^{10-12}$ only

\footnotetext{
a) Author to whom correspondence should be addressed; electronic mail: bpyan@eee.hku.hk
}

limited information was given. In the previous work, the grown emitter-base junction was either an $\mathrm{AlGaAs} / \mathrm{GaAsSb}^{10,11}$ or a $\mathrm{GaAs} / \mathrm{GaAsSb}$ heterojunction, ${ }^{12}$ and the devices showed either poor current gains ${ }^{10,11}$ or large base recombination current with a base current ideality factor of $2 .{ }^{12}$ Recently, we have demonstrated a material combination, i.e., InGaP/GaAsSb/GaAs double-heterojunction bipolar transistors (DHBTs) with low turn-on voltage. ${ }^{13,14}$ For the $\mathrm{InGaP} / \mathrm{GaAsSb} / \mathrm{GaAs}$ DHBTs, an interesting issue is whether or not the InGaP/GaAsSb EB junction and the GaAsSb/ $\mathrm{GaAsSb} / \mathrm{GaAs} \mathrm{BC}$ junction confine carrier transport. In this letter, we study the current transport mechanism in the $\mathrm{InGaP} / \mathrm{GaAsSb} / \mathrm{GaAs}$ DHBTs.

The InGaP/GaAsSb/GaAs DHBT structure was grown on a semi-insulating (100) GaAs substrate by metalorganic chemical vapor disposition. Trimethylgallium, trimethylindium, trimethylantimony, tertiarybutyphosphine, and tertiarybutylarsine were used as the organometallic sources. Carbon and silicon were used as $p$ - and $n$-type dopants, respectively. The device structure consists of a $500 \mathrm{~nm} n>3 \times 10^{18} \mathrm{~cm}^{-3}$ GaAs subcollector, a $500 \mathrm{~nm} n$ $=5 \times 10^{16} \mathrm{~cm}^{-3}$ GaAs collector, a $50 \mathrm{~nm} p=8 \times 10^{18} \mathrm{~cm}^{-3}$ GaAsSb base ( $\mathrm{Sb}$ composition: 10.4\%), a $50 \mathrm{~nm} n=3$ $\times 10^{17} \mathrm{~cm}^{-3}$ InGaP emitter, a $150 \mathrm{~nm} n=4 \times 10^{18} \mathrm{~cm}^{-3}$ GaAs layer, a $50 \mathrm{~nm} n>1 \times 10^{19} \mathrm{~cm}^{-3}$ compositionally graded $\operatorname{In}_{x} \operatorname{GaAs}_{1-x}$ cap layer $(x=0-0.5)$, and a $50 \mathrm{~nm} n>1$ $\times 10^{19} \mathrm{~cm}^{-3}, \mathrm{In}_{0.5} \mathrm{GaAs}_{0.5}$ cap ohmic contact layer. The $\mathrm{Sb}$ composition was confirmed by high-resolution x-ray diffraction measurement. The surface morphology was observed by atomic force microscope and no crosshatched patterns associated with misfit dislocations were observed. This suggests that the GaAsSb base layer is fully strained. The structure was fabricated into devices using optical lithography and chemical wet selective etching for mesa definition.

Figure 1 shows the dependence of current gain on the collector current for a large area device of $100 \times 100 \mu \mathrm{m}^{2}$. The inset in Fig. 1 shows the common-emitter $I-V$ characteristics of the device. The device demonstrates excellent dc performance. The offset voltage is $0.21 \mathrm{~V}$ and the breakdown voltage $B V_{\mathrm{CEO}}$ is about $6 \mathrm{~V}$. It should be noticed that there is still a current gain more than unity even at a collector current 


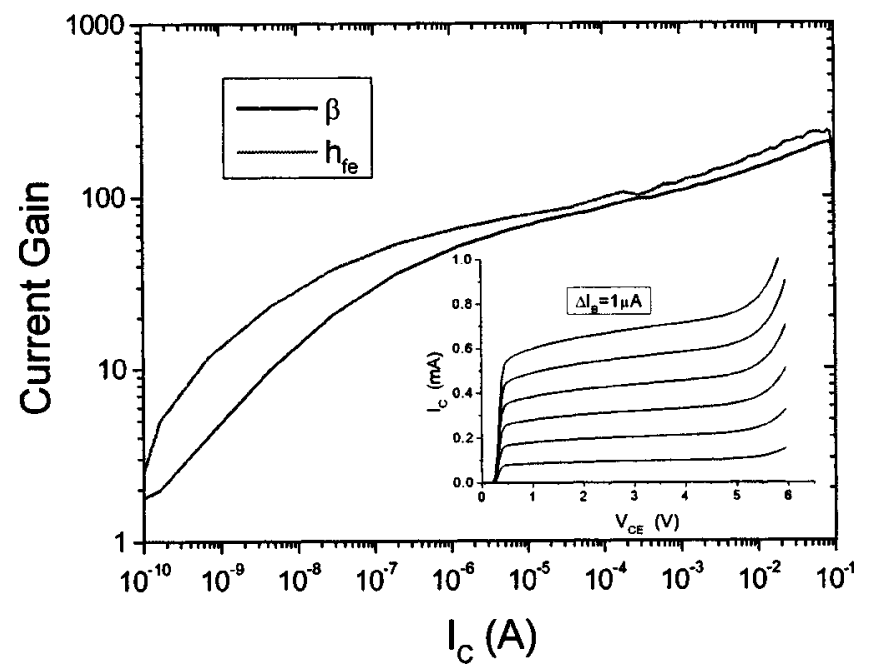

FIG. 1. Direct Current current gain $\beta$ and incremental current gain $h_{f e}$ as a function of collector current $I_{C}$.

of $10^{-10} \mathrm{~A}$, which is probably due to the large valence-band discontinuity and the lower interface recombination at the InGaP/GaAsSb interface. A maximum dc current gain $\beta$ of 207 has been obtained at a collector current of $95 \mathrm{~mA}$. The InGaP/GaAsSb/GaAs DHBTs display a turn-on voltage of $0.914 \mathrm{~V}$ at $J_{C}=1 \mathrm{~A} / \mathrm{cm}^{2}$, which is $0.18 \mathrm{~V}$ lower than that of conventional InGaP/GaAs HBTs, which usually have a turn-on voltage of $1.1 \mathrm{~V}$ at the same collector current density.

In order to determine the current-transport mechanism in the InGaP/GaAsSb/GaAs DHBTs, we have measured the terminal currents of the DHBT both in the forward active mode and in the reverse active mode. It is well known that there are two kinds of current transport mechanisms in bipolar transistors. The first one is the diffusion limitation mechanism, i.e., the terminal current is limited by the transport of carriers across the base layer. In this case, the terminal current only depends on the doping profile and thickness of the base layer, independent of the structure of the emitter-base or the base-collector junction. Therefore, both the terminal currents in the forward active mode and in the reverse active mode should overlap each other and have an ideality factor of unity, ${ }^{15}$ because the base layer is the same in either operation mode. Another transport mechanism is the conduction band barrier limitation of the emitter-base or the basecollector heterojunction, which usually takes place in abrupt heterojunctions. ${ }^{15,16}$ In the case of conduction-band barrier limitation, the terminal current critically depends on the magnitude of the conduction-band barrier. Therefore, the two terminal currents in forward and reverse mode would be apart from each other and have an ideality factor more than unity. ${ }^{17}$

Figure 2(a) shows measured terminal currents of a large area device $\left(100 \times 100 \mu \mathrm{m}^{2}\right)$ in both the forward active mode, and the reverse active mode. When the device is in the forward active mode, the conduction carriers are emitted from the InGaP/GaAsSb EB heterojunction. In contrast, when the device is in the reverse active mode, the conduction carriers are emitted from the $\mathrm{GaAsSb} / \mathrm{GaAs} \mathrm{BC}$ heterojunction. Despite the operational differences in the forward active and reverse active modes of the GaAsSb DHBT, Fig. 2(a) demonstrates that the two terminal currents overlap each other in a large proportion of current range. This finding shows that carriers emitted from either the InGaP/GaAsSb

Downloaded 08 Nov 2006 to 147.8.21.97. Redistribution subject
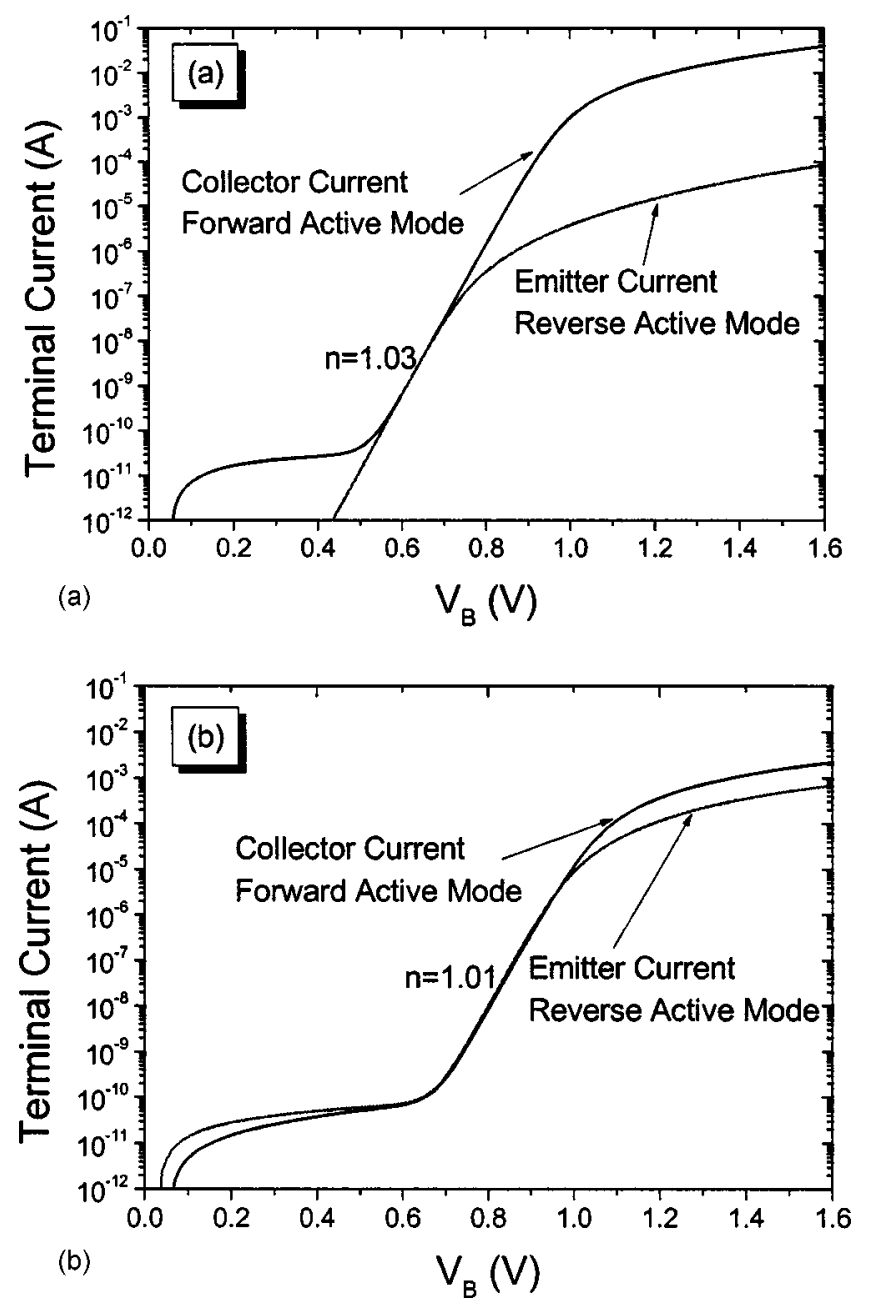

FIG. 2. Measured terminal currents of the InGaP/GaAsSb DHBTs in both forward active mode and the reverse active mode for (a) a large area device $\left(100 \times 100 \mu \mathrm{m}^{2}\right)$ and (b) a small area device $\left(2 \times 30 \mu \mathrm{m}^{2}\right)$.

EB junction or GaAsSb/GaAs BC junction in the GaAsSb DHBTs are limited by the transport across the base layer. This finding is further corroborated from the ideality factors of the terminal currents that are very close to unity. To further verify our conclusion, we also measured the terminal currents in a small area device of $2 \times 30 \mu \mathrm{m}^{2}$, as shown in Fig. 2(b). Figure 2(b) demonstrates again that the two terminal currents are nearly identical in almost the entire current range. It should be noticed that, the overlapping of the terminal currents in Fig. 2(a) does not take place in entire current range. This is attributed to large base and collector resistances, which take a large proportion of $V_{\mathrm{BC}}$, causing the available junction voltage, $V_{\mathrm{BC} j}$, to decrease. Since the carrier transport is not limited by the conduction-band barrier, it is impossible to determine the exact magnitude of the band offset in the emitter-base and the base-collector heterojunctions from this investigation. However, it can still be inferred that the conduction-band offsets at both InGaP/GaAsSb EB junction and $\mathrm{GaAsS} / \mathrm{aAs} \mathrm{BC}$ heterojunction are small enough such that the terminal currents have nearly identical characteristics.

To find whether there is the collector current blocking in the InGaP/GaAsSb/GaAs DHBTs, we measured their common-base $I-V$ characteristics. Figure 3 shows the common-base $I-V$ characteristics of a large area transistor with an emitter area of $100 \times 100 \mu \mathrm{m}^{2}$. At small current AIP license or copyright, see http://apl.aip.org/apl/copyright.jsp 

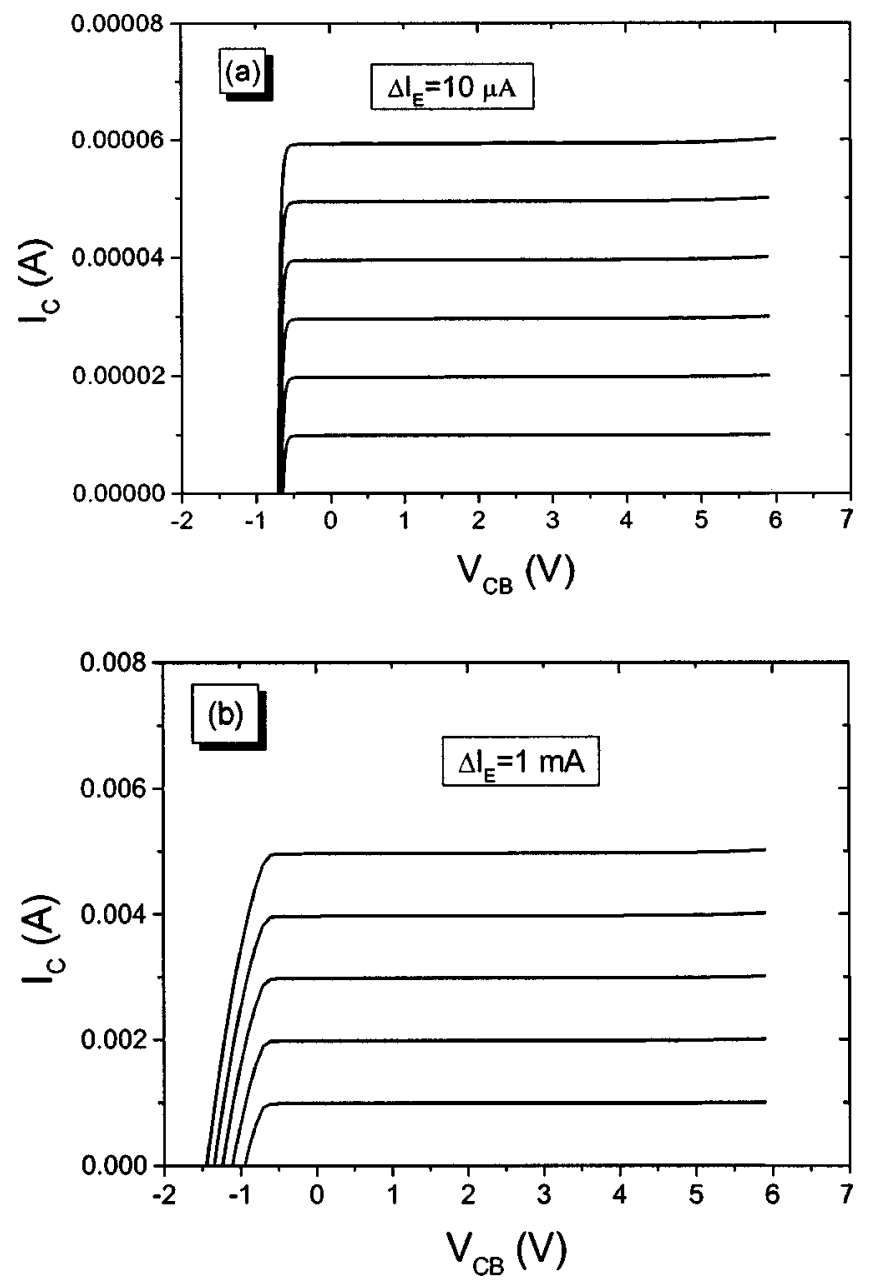

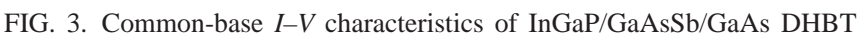
with an emitter size of $100 \times 100 \mu \mathrm{m}^{2}$; (a) at small current and (b) at large current.

level, as shown in Fig. 3(a), the transistor is free of collector current blocking because the turn on near $V_{\mathrm{CB}}=-1 \mathrm{~V}$ is abrupt and the collector current is very nearly independent of $V_{\mathrm{CB}}$ in the turn-on region. At large current level, however, the situation is different. As shown in Fig. 3(b), the turn on near $V_{\mathrm{CB}}=-1 \mathrm{~V}$ is no longer abrupt and the collector current is dependent of $V_{\mathrm{CB}}$ in the turn-on region. We cannot simply regard this situation as the current blocking, because a high base resistance also causes this phenomenon. Using the transmission line method, the base sheet resistance and the base contact resistance were measured as $8300 \Omega / \mathrm{sq}$ and $3.4 \times 10^{-3} \Omega \mathrm{cm}^{2}$, much higher than that of traditional GaAs HBTs. At low current level, the voltage across the base resistance can be negligible and the applied voltage totally drops across the $\mathrm{BC}$ junction. At large current level, however, due to high base resistance, the large proportion of the applied voltage would drop across the parasitic base resistance, causing the available junction voltage to decrease. Further studies by other measurement methods are needed to clarify this point. The work is under way.

In summary, we studied the current transport mechanism of the InGaP/GaAsSb/GaAs DHBTs by measuring both of the terminal currents in forward and reverse mode. The results show that the dominant current transport mechanism in the InGaP/GaAsSb/GaAs DHBTs is the transport of carriers across the base layer. This finding suggests that the conduction-band offset in the InGaP/GaAsSb heterojunction is very small, and the energy band gap offset produced by incorporating $\mathrm{Sb}$ composition into GaAs mainly appears on the valence band, i.e., there is a larger valence band offset in the $\mathrm{InGaP} / \mathrm{GaAsSb}$ heterojunction compared to traditional InGaP/GaAs heterojunction, which effectively blocks hole back-injection current and improves the current gain.

The authors would like to thank the support of the Research Grants Council of Hong Kong Special Administrative Region, China (Project No. HKU7069/02E).

${ }^{1}$ W. Liu, S. K. Fan, T. Henderson, and D. Davito, IEEE Trans. Electron Devices 40, 1351 (1993).

${ }^{2}$ W. Liu, E. Beam III, T. Kim, and A. Khatibzadeh, Current Trends in Heterojunction Bipolar Transistors, edited by M. F. Chang (World Scientific, Singapore, 1996), pp. 241-301.

${ }^{3}$ R. J. Welty, H. P. Xin, K. Mochizuki, C. W. Tu, and P. M. Asbeck, J. Elast. 46, 1 (2002).

${ }^{4}$ P. M. DeLuca, C. R. Lutz, R. E. Welser, T. Y. Chi, E. K. Huang, R. J. Welty, and P. M. Asbeck, IEEE Electron Device Lett. 23, 582 (2002).

${ }^{5}$ P. C. Chang, C. Monier, A. G. Baca, N. Y. Li, F. Newman, E. Armour, and H. Q. Hou, J. Elast. 46, 581 (2002).

${ }^{6}$ R. E. Welser, P. M. DeLuca, and N. Pan, IEEE Electron Device Lett. 21, 554 (2000).

${ }^{7}$ C. R. Bolognesi, N. Matine, M. W. Dvorak, P. Yeo, X. G. Xu, and S. P. Watkins, IEEE Trans. Electron Devices 48, 2631 (2001).

${ }^{8}$ M. W. Dvorak, C. R. Bolognesi, O. J. Pitts, and S. P. Watkins, IEEE Electron Device Lett. 22, 361 (2001).

${ }^{9}$ R. Teissier, D. Sicault, J. C. Harmand, G. Ungaro, G. Le Roux, and L. Largeau, J. Appl. Phys. 89, 5473 (2001).

${ }^{10}$ B. Khamsehpour and K. E. Singer, Electron. Lett. 26, 965 (1990).

${ }^{11}$ K. Ikossi-Anastasiou, IEEE Trans. Electron Devices 40, 878 (1993).

${ }^{12}$ T. Oka, T. Mishima, and M. Kudo, Appl. Phys. Lett. 78, 483 (2001).

${ }^{13}$ B. P. Yan, C. C. Hsu, X. Q. Wang, and E. S. Yang, IEEE Electron Device Lett. 23, 170 (2002).

${ }^{14}$ B. P. Yan, C. C. Hsu, X. Q. Wang, and E. S. Yang, in the 14th Indium Phosphide and Related Materials Conference, 2002, pp. 169-172.

${ }^{15}$ P. Asbeck, in High-Speed Semiconductor Devices, edited by S. M. Sze (Wiley, New York, 1990), pp. 364-365.

${ }^{16}$ H. Kroemer, Solid-State Electron. 28, 1101 (1985).

${ }^{17}$ W. Liu, S. K. Fan, T. S. Kim, E. A. Beam III, and D. B. Davito, IEEE Trans. Electron Devices 40, 1378 (1993). 